\title{
Intensive induction chemotherapy with C-BOP/BEP for intermediate- and poor-risk metastatic germ cell tumours (EORTC trial 30948)
}

\section{SD Fosså*, , B Paluchowska ${ }^{2}$, A Horwich ${ }^{3}$, G Kaiser ${ }^{4}$, PHM de Mulder ${ }^{5}$, O Koriakine ${ }^{6}$, AT van Oosterom ${ }^{7}$, L de Prijck ${ }^{8}$, L Collette ${ }^{8}$, R de Wit ${ }^{9}$ and the EORTC GU Group}

'Department of Oncology, Norwegian Radium Hospital and University of Oslo, Oslo, Norway; ${ }^{2}$ Department of Urology, Maria Sklodowska - Curie Memorial Cancer Center, Warsaw, Poland; ${ }^{3}$ Department of Academic Radiotherapy, Royal Marsden Hospital, Sutton, UK; ${ }^{4}$ Department of Oncology, Klinikum Nürnberg, Nürnberg, Germany; ${ }^{5}$ Department of Internal Medicine, Sint Radboud University Hospital, Nijmegen, The Netherlands; ${ }^{6}$ Department of Urology, Medical Radiological Research Center, Obninsk (formerly: Cancer Research Center, Moskow, Russia), Russia; ${ }^{7}$ Department of Oncology, Universitair Ziekenhuis Gasthuisberg, Leuven, Belgium; ${ }^{8}$ Data Center, Data Management Unit, EORTC Data Center, Brussels, Belgium; ${ }^{9}$ Department of Medical Oncology, Erasmus Medical Center, Rotterdam, The Netherlands

New chemotherapy regimens are continuously explored in patients with high-risk malignant germ cell tumours (MGCTs). This multicentre phase II trial assessed the efficacy and toxicity of C-BOP/BEP chemotherapy in intermediate and poor prognosis MGCT (IGCCCG criteria). C-BOP/BEP treatment consisted of cycles of cisplatin, vincristine, bleomycin and carboplatin, followed by one cycle of vincristine and bleomycin and three cycles of BEP (bleomycon, etoposide, cisplatin). The trial was designed to demonstrate a I-year progression-free survival rate of $80 \%$, that is, to exclude a I-year rate of $70 \%$ or less, with a one-sided significance level of $5 \%$. Secondary end points included toxicity, overall survival and the postchemotherapy complete response rate. In total, 16 European hospitals entered 66 eligible patients (intermediate prognosis group: 37; poor prognosis group: 29). A total of 45 patients (68.2\%, 95\% confidence interval $(95 \% \mathrm{Cl}$ ): 56.9-79.4\%) achieved a complete response (intermediate prognosis: 30; poor prognosis: 15). After a median observation time of 40.4 months (range: 13.7-66.3), the I-year progression-free survival rate was $81.8 \% 95 \% \mathrm{Cl}$ : 72.5-91.1\%). The 2-year overall survival was $84.5 \%$ (95\% Cl: 75.6-93.3\%). In all, $5 \mathrm{I}$ patients experienced at least one episode of $\mathrm{WHO}$ grade 3/4 leucopenia, and at least one event of grade 3/4 thrombocytopenia occurred in 30 patients. There was no toxic death. With an $82 \%$ I-year progression-free survival and a lower limit of the $95 \% \mathrm{Cl}$ above $70 \%$, the efficacy of C-BOP/BEP is comparable to that of published alternative chemotherapy schedules in high-risk MGCT patients. The treatment's toxicity is manageable in a multicentre setting. In poor prognosis patients, C-BOP/BEP should be compared to standard chemotherapy of four cycles of BEP.

British Journal of Cancer (2005) 93, 1209-1214. doi:10.1038/sj.bjc.6602830 www.bjcancer.com

Published online 25 October 2005

(C) 2005 Cancer Research UK

Keywords: intermediate and poor prognosis metastatic germ cell tumours; bleomycin; carboplatin; vincristine; cisplatin; etoposide

In patients with metastatic germ cell tumour (MGCT), four cycles of $\mathrm{BEP}$ regimen (bleomycin, etoposide, cisplatin) are considered to be the standard chemotherapy, even in patients belonging to the intermediate and poor prognosis groups defined by the International Germ Cell Collaborative Consensuses Group (ICCCCG) (IGCCCG, 1997). Nevertheless, many attempts have been undertaken to improve the outcome of these patients by the introduction of new chemotherapeutic agents, the use of alternating drug combinations, high-dose chemotherapy schedules or chemotherapy schedules that apply drugs at high density (Table 1). Several

*Correspondence: Professor SD Fosså, Rikshospitalet - Radiumhospitalet Trust, Department of Clinical Cancer Research, Montebello, NO 0310 Oslo 3, Norway; E-mail: s.d.fossa@klinmed.uio.no

Received 8 August 2005; revised 14 August 2005; accepted 19 September 2005; published online 25 October 2005 research groups have retrospectively categorised their patients by the IGCCCG classification system and have demonstrated survival rates superior to those shown in the first report of the IGCCCG for patients belonging to the poor prognosis group.

Based on the schedule described by Wettlaufer et al (1984), the Royal Marsden Hospital in the late 1980s started to develop an 'intensive induction regimen' in an effort to overcome rapid tumour cell proliferation (Horwich et al, 1989a, 1994b). During the first 4 weeks, cisplatin, vincristine and bleomycin (BOP) were administered with a 7-day interval, followed by a further two cycles of bleomycin and vincristine (BO), and thereafter by three cycles of $\mathrm{BEP}$. The final C-BOP/BEP regimen contained a moderate dose of carboplatin $(\mathrm{C})$ in order to achieve a higher total dose of platinum without increasing toxicity. Of 21 patients treated between 1989 and 1992 at the Royal Marsden, 18 were still alive and disease free after a follow-up of 36 months, resulting in a 2 -year survival of $90 \%$. A subsequent extended phase II study confirmed the 
Table I Chemotherapy and outcome in patients with metastatic germ cell tumours belonging to the intermediate- and high-risk group (IGCCCG criteria)

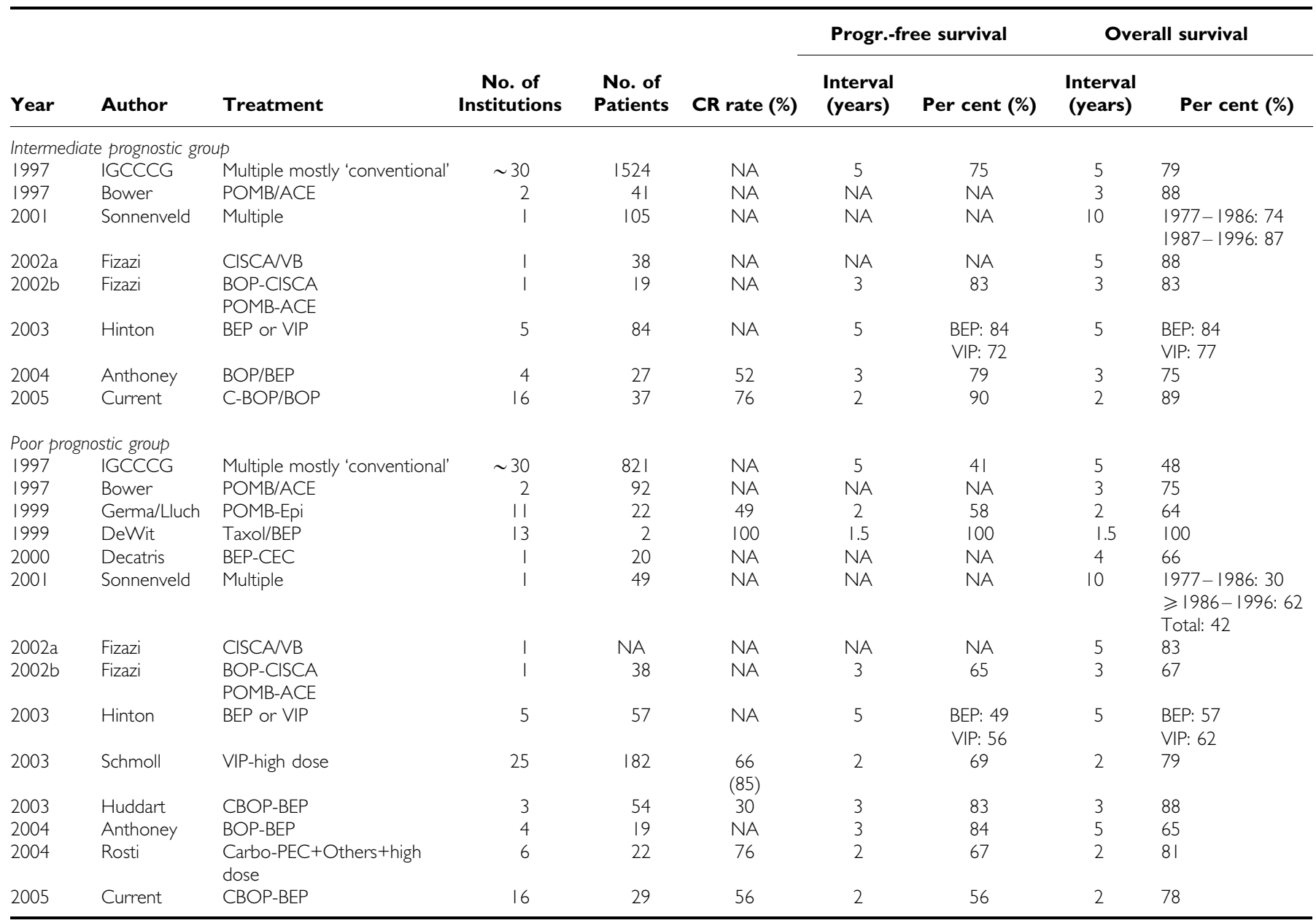

promising single-centre results in 54 patients with unfavourable risk using the Royal Marsden classification system (Christian et al (2003)). This trial performed in three experienced oncological units documented survival rates that were comparable to those achieved by the use of high-dose chemotherapy with autologous haematological stem cell support (Schmoll et al, 2003).

Based on these promising results, a prospective multicentre trial using the C-BOP/BEP regimen seemed warranted in patients belonging to the intermediate- and high-risk groups categorised according to the international classification system. Therefore, in 1998, the EORTC GU group decided to further assess the C-BOP/BEP chemotherapy schedule with the aim, in a prospective multicentre setting, to evaluate the regimen's feasibility and toxicity, to estimate the complete response rate and to establish the progression-free and overall survival.

\section{PATIENTS AND METHODS}

\section{Patients}

Eligible patients had histologically confirmed germ cell cancer (seminoma or nonseminoma) and had to be of intermediate or poor prognosis according to the IGCCCG classification system. They should be aged between 18 and 65 years, without major organ dysfunction unless caused by the malignant disease. All patients had to give informed consent, and consent from local ethical boards had to be obtained. Patients with previous chemotherapy and/or a second malignancy, except a basal cell skin cancer, were ineligible as were those with a creatinine clearance below $40 \mathrm{ml} /$ min, unless this was due to obstructive uropathy which could be relieved by nephrostomy or stenting. Previous radiotherapy was not an exclusion criterion.

\section{Pretreatment evaluation}

Pretreatment evaluation comprised physical examination, CT scanning of the abdomen and chest, measurement of serum alpha-foetoprotein (AFP), human choriogonadotropin (HCG) and lactate dehydrogenase (LDH). A CT scan or an MRI scan of the brain had to be performed in patients presenting with CNS symptoms, those with a serum HCG $>1 \times 10^{5} \mathrm{IU} / \mathrm{l}$ or in patients with more than 20 lung metastases.

\section{Study design}

All patients had to be registered at the EORTC Data Center in Brussels before the onset of chemotherapy or latest within the first 2 weeks after start. Chemotherapy comprised an initial intensive induction phase with C-BOP/BO for 6 weeks followed by three 3 -weekly cycles of BEP with reduced doses of bleomycin (Table 2). 
Table 2 C-BOP/BEP treatment regimen

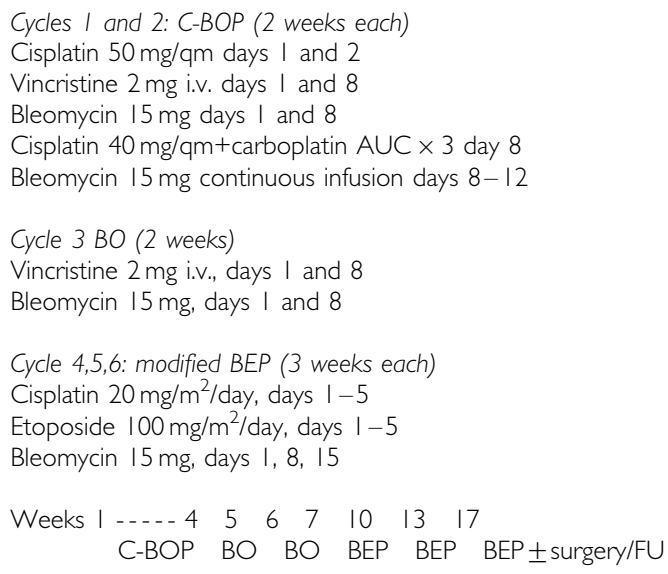

The C-BOP phase consisted of two identical 2-week cycles. The carboplatin dose applied on day 8 of these 2 -week cycles was in milligrams: $3 \times($ GFR (glomerular filtration rate $)+25)$. Bleomycin $15 \mathrm{mg}$ was applied over $15 \mathrm{~min}$ on days 1 and 8. During days 8-12, a total of $75 \mathrm{mg}$ bleomycin was given as continuous infusion $\left(15 \mathrm{mg} \mathrm{day}^{-1}\right)$. The two C-BOP cycles were, after 2 weeks, followed by cycle 3 , consisting of bleomycin and vincristine. Cycles 4, 5 and 6 of BEP chemotherapy, given with reduced doses of bleomycin $\left(45 \mathrm{mg} \mathrm{cycle}^{-1}\right)$, were applied at 3 weekly intervals. Dose reductions during the BEP cycle were planned only if there had been an episode of neutropenic fever or sepsis in the previous cycle, in which case the etoposide was given at $100 \mathrm{mg} \mathrm{m}^{-2}$ day $^{-1}$ for only 3 days during the following cycle.

After chemotherapy, all patients with nonseminomatous germ cell tumours and normalised serum tumour markers, but with evidence of residual disease, had to undergo resection of the residual tumour masses. As $80-90 \%$ of the postchemotherapy residual masses in patients with seminoma contain completely necrotic tumour tissue and major surgery has been shown to be somehow risky in these cases, routine postchemotherapy surgery was not recommended in seminoma patients.

\section{Response evaluation}

Patients had to be evaluated for response within 4 weeks after commencing cycle 6 or immediately after their postchemotherapy surgery. Patients with normal tumour markers and no clinical or radiological evidence of residual masses were classified as complete responders. If 'no tumour', 'necrosis only' or 'mature teratoma only' was detected in the completely resected specimen, the case was also categorised as complete response.

Patients who after six cycles had persistently elevated tumour markers, although reduced compared to the pretreatment values, and/or who had residual vital malignant tumour in the operation specimen belonged to the category of incomplete response. Progression at any time after start of C-BOP/BEP was defined as rising serum tumour markers above the upper limit of the institution's normal range or occurrence of new metatstatic lesions or by $a \geqslant 25 \%$ size increase of pretreatment tumour masses. The rare development of a growing teratoma, documented by histological examination, represented an exception from this definition. Patients who went off study before they had completed the six cycles due to early death due to MGCT or due to progression were categorised as treatment failures. Patients with normal serum tumour markers after chemotherapy, but with residual masses, who did not undergo postchemotherapy surgery were regarded as inevaluable for response but were included in the evaluation of the response rate.

\section{Follow-up}

Completely responding patients and those inevaluable for response did not receive further treatment, whereas those with incomplete response, treatment failure or progression were treated according to the clinical investigator's discretion. Data on type and outcome of such salvage treatment were, however, not collected within the trial.

All patients were to be followed-up for the event of progression. Follow-up examinations were to be performed with 2-3-month intervals during the first year and with increasing intervals thereafter. Biopsy was recommended in seminoma patients with residual masses if no size reduction had recurred after 6 months observation. After progression, all patients were followed for survival.

\section{Statistical considerations}

The primary trial end point was the 1-year progression-free survival rate. The trial was designed to exclude a 1-year rate of $70 \%$ or less with $95 \%$ confidence interval $(95 \% \mathrm{CI})$ under the hypothesis that the true rate was $80 \%$ (i.e. a lower limit of the $95 \%$ CI for the 1 -year progression-free survival rate $>70 \%)$. Under this condition, 62 evaluable patients had to be treated in this study. Using the Kaplan-Meier technique, overall and progression-free survival were calculated from the first day of chemotherapy to the date of death (or progression) or to the date of most recent follow-up, whichever came first.

\section{Disclosure}

This publication was supported by grant numbers 5U10-CA1148824 to 5U10-CA11488-35 from the National Cancer Institute (Bethesda, Maryland, USA). Its contents are solely the responsibility of the authors, and do not necessarily represent the official views of the National Cancer Institute.

\section{RESULTS}

From June 1996 until March 1998, 16 institutions registered 79 patients; 13 of them were eventually deemed ineligible (registration $>14$ days after treatment start: 11; erroneous prognosis-group classification: two). Of the 66 eligible patients, 39 belonged to the intermediate prognosis group and 27 to the poor prognosis group (Table 3). The median age of the 65 males and one female (ovarian cancer) subject was 29 years (range 18-50). One patient in the intermediate prognosis group had relapsed with bone metastases after radiotherapy for stage 1 seminoma, and one patient with a poor prognosis nonseminoma had radiotherapy 1 week before trial entry due to imminent spinal cord compression. The median observation time was 40.4 months (range: 13.7-66.3 months). All but six patients were observed to death or a minimum of 2 years.

\section{Treatment}

Of the 66 patients, 62 received all six planned cycles (Table 4). One patient died of progressive MGCT after the first cycle, and three other men progressed after five treatment cycles. The relative median cumulative dose of the four drugs of the C-BOP phase was $>90 \%$ of the expected dose, as compared to $86 \%$ for each of the three drugs of the BEP schedule. Dose modifications were frequently required (postponement of at least one cycle: 33 patients; dose reduction during at least one cycle: seven patients; 
Table 3 Patient characteristics

\begin{tabular}{|c|c|c|c|}
\hline & \multicolumn{3}{|c|}{ Risk group } \\
\hline & Intermediate & High & Total \\
\hline Number of patients entered & 48 & 31 & $79^{b}$ \\
\hline Ineligible $\mathrm{a}^{\mathrm{a}}$ & 9 & 4 & 13 \\
\hline Eligible (years) & 39 & 27 & 66 \\
\hline Age (median, range) & $29(18-50)$ & $28(|8-4|)$ & $29(18-50)$ \\
\hline \multicolumn{4}{|l|}{ Site } \\
\hline Testis & 35 & 17 & 52 \\
\hline Extragonadal & 4 & 10 & 14 \\
\hline Retroperitoneal & 4 & 4 & 8 \\
\hline Mediastinal & 0 & 4 & 4 \\
\hline Other $^{b}$ & 0 & 2 & 2 \\
\hline \multicolumn{4}{|l|}{ Histology } \\
\hline Seminoma & 2 & 0 & 2 \\
\hline Nonseminoma & 37 & 27 & 64 \\
\hline Previous radiotherapy & । & । & 2 \\
\hline \multicolumn{4}{|c|}{ Tumour sites at start of treatment } \\
\hline Abdominal LN & 37 & 22 & 59 \\
\hline Mediastinal LN & 5 & ।1 & 16 \\
\hline Supraclav LN & 4 & 3 & 7 \\
\hline Lung & 16 & 13 & 29 \\
\hline Liver & 0 & 9 & 9 \\
\hline Bone & I & 0 & I \\
\hline Brain & 0 & 2 & 2 \\
\hline Other & 2 & I & 3 \\
\hline
\end{tabular}

${ }^{a}$ O wing to registration $>2$ weeks after treatment start (I I patients) or inappropriate serum marker values (2). ' ${ }^{b}$ Ovary (I) and abdominal (I). 'Lymph nodes.

Table 4 Maximal acute toxicity

\begin{tabular}{|c|c|c|c|c|}
\hline & \multicolumn{4}{|c|}{ Number of patients (\%) } \\
\hline & WHO 0-I & 2 & 3 & 4 \\
\hline Haemoglobin & 6 & 25 & $27(40.9)$ & $8(12.1)$ \\
\hline Neutrophils ${ }^{\mathrm{a}}$ & 43 & 3 & $9(13.6)$ & $9(13.6)$ \\
\hline Platelets & 23 & 13 & $12(18.2)$ & $18(27.3)$ \\
\hline WBC & 4 & 11 & $40(60.6)$ & $11(16.7)$ \\
\hline Infection & 44 & 15 & $4(6.1)$ & $3(4.5)$ \\
\hline Febrile neutropenia & 51 & 5 & $8(12.1)$ & $2(3.0)$ \\
\hline Mucositis & 49 & 12 & $3(4.5)$ & $2(3.0)$ \\
\hline Ototoxicity ${ }^{\mathrm{b}}$ & 56 & 9 & & \\
\hline Sensory neuropathy & 52 & 10 & $3(4.5)$ & I (1.5) \\
\hline Pulmonary toxicity & 57 & 5 & $2(3.0)$ & $2(3.0)$ \\
\hline Cutaneous toxicity & 52 & 12 & $1(1.5)$ & । (1.5) \\
\hline Any haematological toxicity & 0 & 9 & $27(4.9)$ & $30(45.5)$ \\
\hline Any nonhaematological toxicity ${ }^{c}$ & 8 & 25 & $25(37.9)$ & $8(12.1)$ \\
\hline Any toxicityc ${ }^{c}$ & 0 & 7 & $27(40.9)$ & $32(48.5)$ \\
\hline
\end{tabular}

aMissing in two patients. 'Missing in one patient. 'Also including fatigue, nausea, vomiting, diarrhoea, constipation, other neurological toxicity and other side effects.

discontinuation of a drug during at least one cycle: seven patients; premature discontinuation of at least one cycle: 13 patients).

Overall, haematological toxicity was the most frequent reason for dose modification (30 patients). Pulmonary and renal toxicity

\section{A Progression-free survival by risk group}

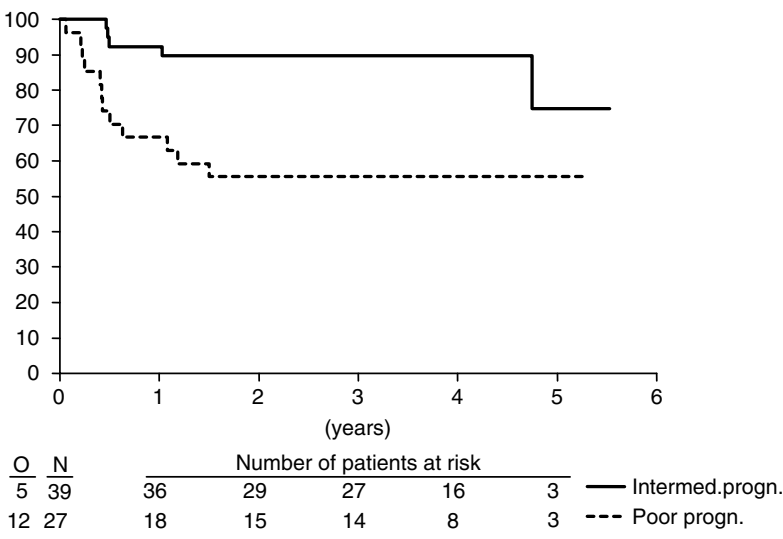

\section{B Duration of survival by risk group}

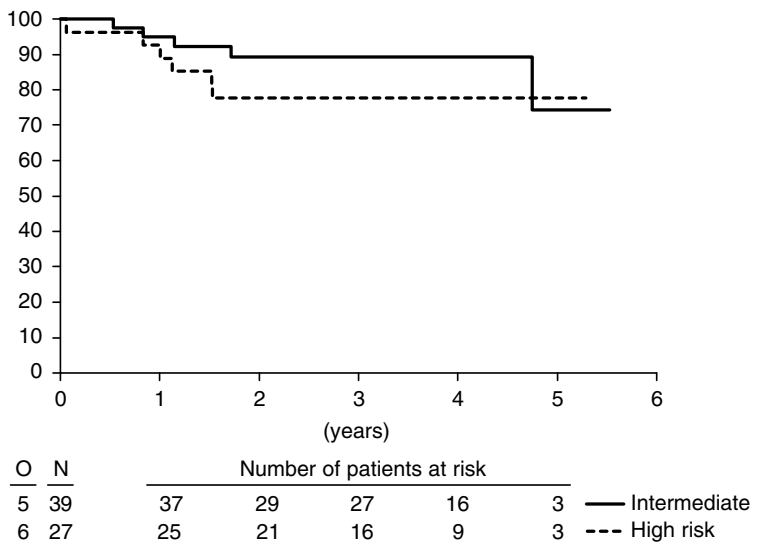

Figure I Progression-free (A) and overall (B) survival in patients with MGCT of the intermediate (37 patients) and poor prognosis (29 patients) group.

led to dose modification in five and four patients, respectively. Resections of postchemotherapy residual masses were performed in 44 patients (intermediate-risk group: 25; high-risk group: 19). Viable cancer cells were found in one patient from each risk group. Of the 44 patients, 19 displayed postchemotherapy necrosis/ fibrosis, and 22 had mature teratoma (50\%), without statistical difference between the two subgroups as to histopathological outcome.

\section{Outcome}

Immediately after chemotherapy or after their postchemotherapy surgery, 45 of all 66 patients (68.2\%, 95\% CI: $56.9-79.4 \%)$ had a complete response (intermediate group: 30 patients (76\%); highrisk group: 15 patients (56\%)). Treatment failure was recorded in the four patients who did not complete the six planned cycles. Incomplete response was recorded in six patients, and 11 were inevaluable for response. At the end of the observation time, progression had occurred in a total of 17 patients (26\%); intermediate-risk group: five patients; high-risk group: 12 patients, including the four patients with treatment failure. At the date of last observation, 55 patients were alive and 11 were dead, 10 of them due to their MGCT. (The 11th patient died tumour-free in a car accident.)

The 1-year progression-free survival for all patients was $81.8 \%$ (95\% CI: 72.5-91.1\%). The 2-year progression-free survival for the 
intermediate- and high-risk group was $89.7 \%$ (95\% CI: $80.2-$ $99.3 \%$ ) and $55.6 \%$ (95\% CI: 36.8-74.3\%), respectively (Figure 1A). The 1- and 2-year overall survivals were, respectively, $93.9 \%(95 \%$ CI: $88.2-99.7 \%)$ and $84.5 \%$ (95\% CI: 75.6-93.3\%) (Figure 1B).

\section{Toxicity}

A total of 59 patients experienced grade 3 or 4 toxicity at least once (Table 4 ). Grade 4 haematological toxicity was seen in $40.9 \%$ of the patients, with thrombocytopenia being the most frequent side effect. Four patients developed grade $3 / 4$ pulmonary toxicity and 14 patients developed at least one period of grade 3/4 infection or febrile neutropenia. There was no toxic death. G-CSF support was administered at least once to 23 patients.

\section{DISCUSSION}

With an $81.8 \%$ observed 1-year progression-free survival and a lower limit of the $95 \%$ CI above $70 \%$, this phase II study reached its target demonstrating results of a true 1-year progression-free survival rate of $>80 \%$. The 2 -year overall survival rates in, respectively, intermediate and poor prognosis patients were 89 and $78 \%$. The C-BOP/BEP schedule was feasible in a multicentre setting with predictable and manageable short-term toxicity without any toxic death.

In patients with metastatic germ cell tumours of unfavourable prognosis, attempts to improve the outcome of the standard regimen BEP as induction chemotherapy have focused on three approaches: firstly, intensification of cisplatin application; secondly, introduction of new drugs together with the sequential use of alternating drug combinations; and thirdly, increasing the cumulative doses of the cytotoxic, drugs including the use of highdose chemotherapy followed by autologous stem cell support. Not rarely, clinical investigators have combined these strategies.

Intensification did not improve the 1-year failure-free survival rate in the EORTC GU group's phase III study that in poor prognosis patients (Royal Marsden Hospital categorisation system) compared three cycles of BOP (bleomycin, vincristine, cisplatin) given every 10 days followed by three cycles of VIP-B (etoposide, ifosfamide, cisplatin, bleomycin) with four cycles BEP plus two cycles of EP (Kaye et al, 1998). Concerning the introduction of new agents, four courses of VIP were compared with four cycles of BEP (de Wit et al, 1998b), but both regimens led to similar 2-year failure-free survival (VIP: 64\%; BEP: 60\%) and 2-year overall survival (VIP: 74\%; BEP: 71\%). The greatest experience with the use of alternative drugs has been with the POMB/ACE regimen (cisplatin, vincristine, methotrexate,bleomycin, actinomycin-D, cyclophosphamide, etoposide) with two institutions treating 339 patients with MGCT over a 20-year period with a median follow-up of 8 years (Bower et al, 1997). In total, 92 patients were retrospectively identified as IGCCC poor prognosis. The POMBEPI regimen, essentially consisting of the components of POMB alternating with a modified VIP regimen, resulted in a 2-year overall survival of $64 \%$ in 22 patients within the poor prognosis group (Germa-Lluch et al, 1999). Taxanes in combination with cisplatin-based chemotherapy have also been tested. In a phase I/II study with BEP combined with Taxol, all 13 evaluable patients with intermediate or poor prognosis MGCT achieved a complete response and none of these patients relapsed with a median follow-up of 18 months (de Wit et al, 1999a). Currently the EORTC GU group conducts a phase III study comparing four cycles of T-BEP with four cycles of BEP in patients with intermediate prognosis features. Fizazi et al (2002a) reported a 5-year overall survival of $88 \%$ in the intermediate prognosis group and $83 \%$ (95\% CI: $58-100 \%$ ) in the poor prognosis group using the CISCA/ VB regimen (cisplatin, cyclophosphamide, adriamycin, vinblastine, bleomycin). The same group described a phase II study using the BOP-CISCA-POMB-ACE regimen comprising eight drugs plus granulocyte colony-stimulating factor (Fizazi et al, 2002b). Investigators of the Genitourinary Group of the French Federation of Cancer Centers have embarked on a prospective trial of BEP $v s$ CISCA (II)/VB (IV) in poor-risk patients (Culine et al, 1997). The third approach implies the attempts to use high-dose combination chemotherapy with autologous haematopoetic stem cell support. In several phase II trials, this strategy has resulted in promising survival rates with acceptable toxicity without toxic death, for example, given as CEC (cisplatin, etoposide, cyclophosphamide) after induction with BEP (Decatris et al, 2000), or as sequential high-dose VIP plus paclitaxel (Hartmann et al, 2002). The German Testicular Cancer Group reported a 79\% 2-year survival in 182 poor prognosis patients (IGCCCG criteria) who were treated with escalating doses of VIP followed by autologous stem cell support (Schmoll et al, 2003). In poor prognosis patients, high-dose schedules using CEC or VIP together with autologous blood stem cell transplantation are currently investigated in prospective randomised trials by the US Intergroup (BEP vs high-dose CEC) and the EORTC GU Group (BEP vs high-dose VIP).

The C-BOP/BEP schedule used in this study principally comprises two manoeuvers to improve the efficacy of induction chemotherapy during the first 6 weeks: an increase of the cumulative cisplatin dose and frequent cycling of the cisplatin, vincristine and bleomycin in an effort to overcome rapid proliferation, together with alternating the C-BOP schedule with BEP. For example, in the C-BOP schedule, the dose intensity of platinum during the first 6 weeks is $63 \mathrm{mg} \mathrm{m}^{-2}$ week $^{-1}$ (based on a carboplatin AUC3 being equivalent to cisplatin $50 \mathrm{mg} \mathrm{m}^{-2}$ ) compared to $50 \mathrm{mg} \mathrm{m}^{-2}$ week ${ }^{-1}$ in the BOP/VIP schedule and $33.3 \mathrm{mg} \mathrm{m}^{-2}$ week $^{-1}$ in the standard BEP. The results of the present study are promising. When $\mathrm{C}-\mathrm{BOP} / \mathrm{BEP}$ is given in a multicentre setting, the complete response rates and the 2-year overall survival rates for, respectively, patients with intermediate and poor prognosis MGCT is at least comparable with the results obtained with other intensive cytotoxic regimens (Table 1). Our 2-year overall survival in the poor prognosis group may seem slightly inferior to Christian et al's figure of $88 \%$ achieved at three large cancer centres. This may be due to differences between poor prognosis patients with MGCT as to the type and number of poor risk factors (Decatris et al, 2000). Interstudy differences in outcome may reflect differences in the prognostic features or patient selection rather than real differences in treatment efficacy. Christian et al's slightly superior survival figure can also be viewed as a consequence of broader experience with MGCT patients in general at each of the three involved cancer centres as compared to the experience of institutions with few cases of MGCT (Aass et al, 1991; Collette et al, 1999).

The C-BOP/BEP schedule has been shown to be safe in a multicentre design, with no toxic deaths in the current study. Based on nonrandomised historical studies (International Germ Cell Cancer Collaborative Group, 1997), its superior efficacy compared to BEP cannot be excluded. During the first weeks of the induction chemotherapy, the proportion of myelotoxic drugs in CBOP is less than in the BEP schedule. This may be advantageous in patients who are very sick due to a large tumour burden at the time of diagnosis and who are at particularly high risk of neutropenic fever and sepsis. Nevertheless, the occurrence of 'any grade 3/4 toxicity' in $90 \%$ of the patients and of grade $3 / 4$ haematological toxicity in $77 \%$ warrants that these patients should be managed at institutions with experience in the treatment of MGCT.

Until the ongoing three phase III studies comparing four cycles of BEP with experimental chemotherapy regimens are finalised, BEP remains the standard treatment of MGCT, even in patients with intermediate and poor prognosis features. The current and published results with c-BOP/BEP support ongoing plans to conduct a multicentre phase III study comparing C-BOP with four cycles of BEP in poor prognosis patients. 
1214

\section{Contributions}

The following investigators and centres contributed patients to the study:

SD Fossa, Norwegian Radium Hospital, Oslo, Norway (21); B Paluchowska, Maria Sklodowska - Curie Memorial Cancer Center, Warsaw, Poland (16); A Horwich, Royal Marsden Hospital, Sutton, UK (13); G Kaiser, Klinikum Nürnberg, Nürnberg, Germany (8); $\mathrm{P}$ de Mulder, Sint Radboud University Hospital, Nijmegen, The Netherlands (4); O Koriakine, Medical Radiological Research Center, Obninsk, Russia (formerly: Cancer Research Center, Moskow, Russia) (3); ATM Van Oosterom, Universitair Ziekenhuis Gasthuisberg, Leuven, Belgium (3); C Sternberg, San Camillo and

\section{REFERENCES}

Aass N, Klepp O, Cavallin-Stahl E, Dahl O, Wicklund H, Unsgaard B, Baldetorp L, Ahlstrom S, Fossa SD (1991) Prognostic factors in unselected patients with nonseminomatous metastatic testicular cancer: a multicenter experience. J Clin Oncol 9: 818-826

Anthoney DA, Kaye SB (1999) Treatment of poor prognosis metastatic germ-cell tumours: much heat but, as yet, little light. Ann Oncol 10: 255 258

Bower M, Newlands ES, Holden L, Rustin GJS, Begent RHJ (1997) Treatment of men with metastatic non-seminomatous germ cell tumours with cyclical POMB/ACE chemotherapy. Ann Oncol 8: 477-483

Christian JA, Huddart RA, Norman A, Mason M, Fossa SD, Aass N, Nicholl EJ, Dearnaley DP, Horwich A (2003) Intensive induction chemotherapy with CBOP/BEP in patients with poor prognosis germ cell tumors. J Clin Oncol 21: $871-877$

Collette L, Sylvester RJ, Stenning SP, Fossa SD, Mead GM, de Wit R, de Mulder PH, Neymark N, Lallemand E, Kaye SB (1999) Impact of treating institution on survival of patients with 'poor-prognosis' metastatic nonseminoma. European Organization for Research and Treatment of Cancer Genito-Urinary Tract Cancer Collaborative Group and the Medical Research Council Testicular Cancer Working Party. J Natl Cancer Inst 91(10): 839-846

Culine S, Théodore C, Bekradda M, Farhat F, Terrier-Lacombe MJ, Droz JP (1997) Experience with bleomycin, etoposide, cisplatin (BEP) and alternating cisplatin, cyclophosphamide, doxorubicin $\left(\mathrm{CISCA}_{\mathrm{II}}\right) /$ vinblastine, bleomycin $\left(\mathrm{VB}_{\mathrm{IV}}\right)$ regimens of chemotherapy in poor-risk nonseminomatous germ cell tumors. Am J Clin Oncol 20: 184-188

Decatris MP, Wilkinson PM, Welch RS, Metzner M, Morgenstern GR, Dougall M (2000) High-dose chemotherapy and autologous haematopoietic support in poor risk non-seminomatous germ-cell tumours: an effective first-line therapy with minimal toxicity. Ann Oncol 11: 427-434

De Wit R, Louwerens M, de Mulder PH, Verweij J, Rodenhuis S, Schornagel J (1999a) Management of intermediate-prognosis germ-cell cancer: results of a phase I/II study of Taxol-BEP. Int J Cancer 83(6): 831-833

De Wit R, Stoter G, Sleijfer DT, Neijt JP, ten Bokkel Huinink WW, de Prijck L, Collette L, Sylvetser R (1998b) Four cycles of BEP $v s$ four cycles of VIP in patients with intermediate-prognosis metastatic testicular nonsaeminoma: a randomized study of the EORTC Genitourinary Tract Cancer Cooperative Group. European Organization for Research and Tretament of Cancer. Br J Cancer 78(6): 828-832

Fizazi K, Do KA, Wang X, Finn L, Logothetis CJ, Amato RJ (2002a) A $20 \%$ dose reduction of the original CISCA/VB regimen allows better tolerance and similar survival rate in disseminated testicular non-seminomatous germ-cell tumors: final results of a phase III randomized trial. Ann Oncol 13: $125-134$

Fizazi K, Prow DM, Do KA, Wang X, Finn L, Kim J, Daliani D, Papandreou CN, Tu SM, Millikan RE, Pagliaro LC, Logothetis CJ, Amato RJ (2002b) Alternating dose-dense chemotherapy in patients with high volume disseminated non-seminomatous germ cell tumours. $\mathrm{Br}$ J Cancer 86: $1555-1560$
Forlanini Hospitals (formerly: San Raffaele Hospital), Roma, Italy (2); G Mead, Royal South Hants Hospitaln Southampton, UK (2); JB Vermorken, Universitair Ziekenhuis Antwerpen, Edegem, Belgium (1); JJ Croles, Bosh Medicentrum, s'Hertogenbosch, The Netherlands (1); R de Wit, Erasmus Medical Center, Rotterdam, The Netherlands (1); HJ Keizer, University Hospital, Leiden, The Netherlands (1); A Bono, Ospedale di Circolo e Fundacione Macchi, Varese, Italy (1); M Williams, Addenbrooke National Health Service, Cambridge, UK (1); RE Coleman, Weston Park Hospital, Sheffield, UK (1).

$\mathrm{L}$ de Prijck was the data manager at the EORTC Data Centre, responsible for this trial. L Collette was the statistician at the Data Centre.
Germa-Lluch JR, Garcia del Muro X, Tabernero JM, Sanchez M, Aparicio J, Alba E, Barnadas A (1999) BOMB/EPI intensive alternating chemotherapy for IGCCC poor-prognosis germ-cell tumors: The Spanish Germ-Cell Cancer Group experience. Ann Oncol 10(3): 289-293

Hartmann JT, Schleucher N, Metzner B (2002) Phase I/II study of sequential high dose VIP plus paclitaxel in poor prognosis germ cell tumors. Ann Oncol 13(suppl 5): 96 (abstract 348P)

Hinton S, Catalano PJ, Einhorn LH, Nichols CR, David-Crawford E, Vogelzang N, Trump D, Loehrer Sr PJ (2003) Cisplatin, etoposide and either bleomycin or ifosfamide in the treatment of disseminated germ cell tumors. Cancer 97: 1869-1875

Horwich A, Brada M, Nicholls J, Jay G, Hendry WF, Dearnaley D, Peckham MJ (1989a) Intensive induction chemotherapy for poor risk non seminomatous germ cell tumours. Eur J Cancer 25: 177-184

Horwich A, Dearnaley DP, Norman A, Nicolls J, Hendry WF (1994b) Accelerated chemotherapy for poor prognosis germ cell tumours. Eur $J$ Cancer 30: 1607-1611

International Germ Cell Cancer Collaborative Group (IGCCCG) (1997) International Germ Cell Consensus Classification: a prognostic factorbased staging system for metastatic germ cell cancers. J Clin Oncol 15(2): $594-603$

Kaye SB, Mead GM, Fossa SD, Cullen M, deWit R, Bodrogi I, vanGroeningen C, Sylvester R, Collette L, Stenning S, De Prijck L, Lallemand $\mathrm{E}$, deMulder $\mathrm{P}$ (1998) Intensive induction-sequential chemotherapy with BOP/VIP-B compared with treatment with BEP/EP for poor-prognosis metastatic nonseminomatous germ cell tumor: a randomized Medical Research Council/European Organization for research and treatment of cancer study. J Clin Oncol 16: 692-701

Rosti G, De Giorgi U, Wandt H, Lioure B, Leyvraz S, Kolbe K, Papiani G, Ballardini M, Kulekci A, Demirer T, Solid Tumours Working Party (2004) First-line high-dose chemotherapy for patients with poor prognosis extragonadal germ cell tumors: the experience of the European Bone Marrow Transplantation (EBMT) Solid Tumors Working Party. Bone Marrow Transplant 34: 1033-1037

Schmoll HJ, Kollmannsberger C, Metzner B, Hartmann JT, Schleucher N, Schoffski P, Schleicher J, Rick O, Beyer J, Hossfeld D, Kanz L, Berdel WE, Andreesen R, Bokemeyer C (2003) Long-term results of first-line sequential high-dose etoposide, ifosfamide, and cisplatin chemotherapy plus autologous stem cell support for patients with advanced metastatic germ cell cancer: an extended phase I/II study of the German Testicular Cancer Study Group. J Clin Oncol 21: 4083-4091

Sonneveld DJA, Hoekstra HJ, van der Graaf WT, Sluiter WJ, Mulder NH, Willemse PH, Koops HS, Sleijfer DT (2001) Improved long-term survival of patients with metastatic nonseminomatous testicular germ cell carcinoma in relation to prognostic classification systems during the cisplatin era. Cancer 91: 1304-1315

Wettlaufer JN, Feiner AS, Rosinson WA (1984) Vincristine, cisplatin and bleomycin with surgery in the management of advanced metastatic non seminomatous testis tumours. Cancer 53: 203-209 